\title{
Pros

\section{LA AUTOFICCIÓN COMO DIALÉCTICA ENTRE LO HISTÓRICO Y LO BIOGRÁFICO EN LA OBRA DE JAVIER CERCAS}

José ANTONIO Vila SÁNCHEZ

Universitat Pompeu Fabra, Barcelona

A partir del año 2000, buena parte de la obra de Javier Cercas se ha articulado sobre la noción de "autoficción" y sus diversas inflexiones. En este trabajo estudiaremos la utilización que Cercas hace de esos recursos retóricos, que podemos considerar característicos de la autoficción, a la par que veremos con qué finalidad dichas estrategias textuales son empleadas. Por ello nuestro estudio se centrará en Relatos reales (2000), Soldados de Salamina (2001), La velocidad de la luz (2005), "La verdad de Agamenón" (2006 -cuento incluido en el volumen misceláneo homónimo-) y Anatomía de un instante (2009). Al margen, por tanto, van a quedar El móvil (1987), El inquilino (1989), El vientre de la ballena (1997) y Las leyes de la frontera (2012). Obras que, si bien comparten con las antecitadas ingredientes temáticos y formales, se apartan claramente de la noción de "autoficción" tal como la acotamos en lo siguiente, y en consecuencia se hallan fuera de los límites de este trabajo.

Aunque no es este el lugar para reseguir la génesis del concepto de "autoficción", son necesarias algunas consideraciones preliminares. Partimos de la noción propuesta por Doubrovsky (1977) y el desarrollo de la idea en Alberca (2007 y 2009). Insistimos en los elementos que señala Alberca como privativos de la autoficción: a) la identidad entre autor, narrador y personaje protagonista (2009: 14) b) que esta identidad sea reconocible por parte del lector (2007: 31). A las condiciones de Alberca añadimos el matiz apuntado por Lecarme (1993): que el intitulado genérico indique claramente que se trata de una novela (obra de ficción) para que pueda hablarse de "autoficción" (1993: 227). 
Nuestra argumentación se sitúa en la línea "contractualista" sostenida por Lejeune para la autobiografía (1975 y 1986), según la cual la intitulación genérica del libro, que remite a elementos paratextuales como la cubierta, establece un "pacto de lectura" tácito que compromete al autor firmante a una referencialidad susceptible de verificación externa, en la misma medida que un escrito jurídico, histórico o científico (1975: 13-45)ํ. Las autoficciones, al contrario, en tanto que presentadas explícitamente como ficción, no son susceptibles de verificación referencial ${ }^{2}$, aunque no se diferencien formalmente de una narración autobiográfica.

Ahí reside el equívoco de la autoficción, que emana de aplicar a una novela los modos de enunciación ${ }^{3}$ característicos de la autobiografía, por eso, las autoficciones problematizan la identidad entre autor, narrador y personaje (Alberca 2007: 29), cuya unidad es condición sine qua non para que haya literatura autobiográfica (Lejeune 1975: 15) ${ }^{4}$. De ello deducimos que las autoficciones inducen a un equívoco intencionado en el "horizonte de expectativas" del lector (Iser 1974 y 1976, Jauss 1970), pues "la autoficción se ofrece con plena conciencia del carácter ficticio del yo y, por tanto, [...] no es prioritario ni representa una exigencia delimitar la veracidad autobiográfica" (Alberca 2007: 32). Esa "vacilación interpretativa" (Alberca 2007: 33) es el resultado de la naturaleza soi disant híbrida (novelesco-autobiográfica) de las autoficciones, que "simulan una autobiografía verdadera y al simularlo podrían serlo de verdad o no" (Alberca 2009: 14). La apariencia híbrida "proviene sobre todo de la identidad nominal, explícita o implícita, del protagonista con el autor de la obra, cuya firma preside la portada" (Alberca 2009: 15). Si bien Alberca habla de "relatos híbridos" para caracterizar las autoficciones (2009: 14), consideramos más apropiado definirlas como textos de ficción que imitan la enunciación de la autobiografía, con el fin, como mostraremos al estudiar Soldados de Salamina y La velocidad de la luz, de persuadir y seducir al lector.

Pasemos ahora a analizar cómo se crea esa vacilación interpretativa en el ciclo autoficcional que componen Soldados de Salamina, La velocidad de la luz y "La verdad de Agamenón". Comenzando por Soldados de Salamina, vemos que

\footnotetext{
${ }^{1}$ En la misma línea, Bajtin ha señalado el valor documental que desde la Antigüedad se atribuye a las autobiografías y relatos biográficos, como textos eminentemente referenciales (1975: 282298).

2 Darío Villanueva propone, como esencia de la ficcionalidad, "la renuncia a las pruebas de verificación de lo narrado y al principio de sinceridad por parte del que narra" (1989: 195). Sobre la clásica noción de "pacto narrativo" (Booth 1961) remitimos a Eco (1979: 85) y Pozuelo Yvancos (1988: 233-240).

3 "La enunciación es el acto individual de la locución en el que se muestra el hablante" (Marchese 1978: 127). Del estudio de la enunciación en relación con la narración y sus connotaciones estilísticas en la configuración de los géneros literarios remitimos a Genette (1972, 1977 y 1991) y Todorov (1970a, 1971: 99-111, 1978: 16-17).

${ }^{4}$ Del problemático estatuto de la autobiografía como género "fronterizo" entre lo real y lo ficcional (Pozuelo Yvancos 1993 y 2006), no podemos tratar aquí, remitimos sin embargo también a Alberca (1996 y 1999), Caballé (1995 y 1999), Lejeune (1975 y 1986) y Starobinski (1970). El punto crucial del debate se encuentra en la posibilidad (o imposibilidad) de discriminar cuándo el "yo" en la narración autobiográfica es una persona real y cuándo un personaje (Pozuelo Yvancos 2006: 26).
} 
ahí se da una coincidencia nominal explícita entre narrador, protagonista y autor, los tres responden al nombre de "Javier Cercas". Así como se incluyen elementos autobiográficos reales, se citan, sin ir más lejos, El móvil y El inquilino, en efecto, las dos primeras novelas de Javier Cercas, el autor cuya firma preside la portada del libro:

-Oye, ¿tú no serás el Javier Cercas de El móvil y El inquilino?

El móvil y El inquilino eran los títulos de los dos únicos libros que había publicado, más de diez años atrás, sin que nadie salvo algún amigo de entonces se diera por enterado del acontecimiento. (Cercas 2001: 145)

Sin embargo, Javier Cercas, el "autor empírico" o "real", había publicado también la novela El vientre de la ballena, las crónicas de Relatos reales, los artículos de Una buena temporada (1998), y el estudio académico La obra literaria de Gonzalo Suárez (1993) ${ }^{5}$. Esta manipulación de los datos ofrecidos puede llevar al lector avisado a desconfiar, al menos en parte, de la veracidad de lo que se nos cuenta, y a establecer una distinción entre el "Javier Cercas" personaje y el autor real. Al "Javier Cercas" personaje le casaría entonces la categoría narratológica de "autor implícito representado" (Pozuelo Yvancos 1988: 236), es decir, la instancia autorial que en el texto aparece como autor de Soldados de Salamina, que en este caso es también el narrador de la novela ${ }^{6}$.

De la misma manera, se cita el artículo "Un secreto esencial" (Cercas 2001: 23-26), en el que se narra la peripecia real7 de Rafael Sánchez Mazas durante la Guerra Civil y su fusilamiento frustrado en el santuario del Collell. Ese artículo fue realmente escrito por Javier Cercas -después recopilado en Relatos reales (2000: 153-156)-, y se reproduce íntegramente en la novela. Por último, en Soldados de Salamina se introduce el concepto de "relato real", que es decisivo para entender las estrategias de persuasión del lector que estudiamos. "Javier Cercas", el narrador de la novela, declara: "el libro que iba a escribir no sería una novela, sino sólo un relato real, un relato cosido a la realidad, amasado con hechos y personajes reales" (Cercas 2001: 52).

La introducción de esa paradoja del "relato real"8 subraya la importancia de la equivocidad como estrategia retórica característica de la autoficción, poniendo en primer plano el trasvase en la narración entre lo real y lo ficcional, y

\footnotetext{
${ }^{5}$ Igualmente, como señala Gracia (2001: 245), Cercas trabajaba como profesor universitario y no como periodista, según se dice en la novela (Cercas 2001: 17).

${ }^{6}$ Para una tipología de las voces y niveles en la narración ficcional remitimos a Rimmon-Kennan (1983: 86-105).

7 Javier Cercas ha insistido en la veracidad de lo narrado en ese artículo, citando incluso fuentes historiográficas (2006: 151-155).

${ }^{8}$ En una nueva traslación de lo real a lo ficcional, en Soldados de Salamina se parafrasea la definición del concepto que leemos en el prólogo a Relatos reales: "Todo relato parte de la realidad, pero establece una relación distinta entre lo real y lo inventado: en el relato ficticio domina esto último; en el real, lo primero. Para crear la suya propia, el relato ficticio anhela emanciparse de la realidad; el real, permanecer cosido a ella. Lo cierto es que ninguno de los dos puede satisfacer su ambición: el relato ficticio siempre mantendrá un vínculo cierto con la realidad, porque de ella nace; el relato real, puesto que está hecho con palabras, inevitablemente se independiza en parte de la realidad." (Cercas 2000: 16-17).
} 
recuerda los intercambios recíprocos entre ficción y no-ficción señalados por Genette (1991: 53-76). Pensando precisamente en Soldados de Salamina, Pozuelo Yvancos escribe que en la autoficción:

\begin{abstract}
... el límite entre lo histórico y lo inventado se rompe en la propia fuente del lenguaje [...] lo que hace es ficcionalizar la fuente misma del lenguaje [...] y pueda su escritura nivelar por tanto lo que un novelista ha vivido y lo que ha inventado. "Nivelar" significa ponerlos en un mismo eje de historicidad, pero también en un mismo nivel de ficcionalidad. [...] ¿dónde, fuera del testimonio textual, podría dirimirse la frontera entre lo que realmente se vivió con lo que se imaginó vivido, lo que tuvo lugar y lo que pudo verosímilmente suceder? (Pozuelo Yvancos 2004: 282-283)
\end{abstract}

De ese casi indiferenciable tránsito entre lo real y lo ficticio, el mismo Pozuelo Yvancos señala: "respecto a su forma y al funcionamiento del sistema de enunciación resulta imposible distinguir un relato verídico en primera persona (como es la autobiografía) y un relato fingido que imite fielmente tal acto de lenguaje serio, por el que un sujeto de enunciación narra sus propias experiencias" (2006: 26). En este punto, Pozuelo Yvancos sigue, como nosotros, la línea pautada por Philippe Lejeune: el género autobiográfico (referencial) se diferencia del ficcional (no referencial) menos por sus elementos formales que por el "contrato de lectura"9 que establece genéricamente con el lector (1975: 8). También apunta a ello, de manera implícita, la argumentación de Cercas (2006: 111-114) para diferenciar, como veremos, "autor" de "narrador-personaje" en Soldados de Salamina.

Esa nivelación entre lo histórico y lo ficcional puede verse como una estrategia de persuasión del lector, destinada a crear un extraño efecto de verosimilitud, un "efecto de realidad" (Barthes 1984: 179-187), mezclando lo realmente ocurrido con lo imaginado. Recordemos la paráfrasis de Roland Barthes de la definición aristotélica ${ }^{10}$ : "lo verosímil no corresponde fatalmente a lo que ha sido (esto proviene de la historia) ni a lo que debe ser (esto proviene de la ciencia), sino sencillamente a lo que el público cree posible y que puede ser en todo diferente de lo real histórico o de lo posible científico" (1966a: 14-15). También lo apostillado por Paul Ricoeur: "la verosimilitud no es sólo semejanza con lo verdadero, sino apariencia de lo verdadero" (1984: 393). Esta "apariencia de lo verdadero", la "ilusión referencial" (Barthes 1984: 186), es lo que se persigue con la noción tramposa del "relato real", que se quiere cosido a la realidad, amasado con hechos y personajes reales, pero no deja de ser por ello un relato, esto es una obra de ficción ${ }^{11}$. La inclusión de elementos reales, así como la imitación de

\footnotetext{
${ }^{9}$ La aproximación de Genette es la misma (1991: 53-76), quien habla de "estatuto oficial del texto y horizonte de lectura" (1991: 55). Así como es la misma también la de Hamburger (1957).

${ }^{10}$ Aristóteles (1953: 15-16 y 2002: 53-55).

${ }^{11}$ La verosimilitud, entendida sobre todo como reproducción fiel de la realidad, frente al idealismo y a lo maravilloso de la novela medieval y a los géneros épicos y dramáticos de la Antigüedad, es una característica de la novela moderna que han resaltado los estudiosos (Fowler 1982, Frye 1977, Pavel 2003, Wellek y Warren 1949). Al considerar la idea de "verosimilitud" conviene tener
} 
la enunciación del relato autobiográfico, podrían interpretarse pues como un ejemplo del vínculo propuesto por Darío Villanueva entre la voluntad estilística del "efecto de realidad" con la figura retórica de la evidentia o demostratio, "consistente en la representación viva y detallada de una realidad como si se la pusiese ante los ojos del lector" (2004: 152). Considerada bajo este prisma, la estrategia retórica de la autoficción confirmaría el "continuo dinamismo de formas" que provoca la búsqueda del "efecto de realidad", puesto que el "hecho de que los horizontes de expectativa de la audiencia cambien con relativa rapidez impone la búsqueda de nuevas posibilidades estilísticas y compositivas" (Villanueva 2004: 177).

La muestra más memorable de esa mescolanza de lo histórico y lo imaginado la encontramos en la contraposición entre Sánchez Mazas, personaje histórico, y el antiguo combatiente republicano Miralles, personaje de ficción $\mathrm{n}^{12}$ que encarna al anónimo soldado que en la realidad se apiadó del falangista en la hora de su fusilamiento ${ }^{13}$. Y así como el relato autoficcional busca la "apariencia de lo verdadero", el efecto de verosimilitud o realidad, nivelando lo real y lo imaginario, en el mismo sentido opera la confusión deliberada a la que se induce al lector: hacerle tomar al narrador de la novela por el autor empírico o real, artificio que emana de la estrategia textual de la autoficción, y que Cercas subraya (2006: 111-114) $)^{14}$. Por mucho que el narrador de Soldados de Salamina afirme que eso no es una novela, no por ello deja de ser el libro una novela (los paratextos indican claramente que ese es su estatuto genérico)"15: "en última instancia el lector nunca debe fiarse del todo del narrador de una novela, en particular si ésta está narrada en primera persona [...] La expresión unreliable narrator ${ }^{16}$ -narrador no fidedigno- [...] es [...] un pleonasmo indudable: a fin de cuentas, todo narrador, y en particular si es un narrador en primera persona, es siempre unreliable" (Cercas 2006: 113-114). En esta confusión buscada de autor y narrador encontramos un camuflaje de la naturaleza ficcional del discurso, su fingimiento de la fuerza ilocutiva de los enunciados no ficcionales ${ }^{17}$, que sirve para ganarse la

presente la noción de "mímesis", imitación (Aristóteles 2002, Auerbach 1942, Tatarkiewicz 1976 : 301-324).

12 La naturaleza ficticia de Miralles se insinúa por dos veces en el relato (Cercas 2001: 166 y 170).

${ }^{13}$ En este episodio se muestra además la preocupación ética que anima la escritura de Cercas: "Tanto dal punto di vista letterario quando da quello morale, ciò è davvero miracoloso è il bene, il fatto che ci siano persone buone che, andando oltre la natura umana, che è bestiale, assassina, ripugnante e cannibale, agisce con bontà" (Cercas y Arpaia 2013: 24).

14 Más arriba hemos propuesto la categoría de "autor implícito representado" para el "Javier Cercas" narrador y personaje de Soldados de Salamina.

15 Una lectura concomitante a la nuestra la hallamos en Gracia (2001: 242, 245, 247-248, 253 y 259).

16 Booth postuló, como es harto conocido, la idea de "narrador no fidedigno" en su análisis de las obras de Henry James (1961: 339-374), en contraposición con el "narrador fidedigno" de la literatura realista.

17 Por fuerza ilocutiva o ilocucionaria debe entenderse la capacidad "performativa", ejecutante, de los actos de habla (Austin 1960). Para Austin los enunciados literarios -ficcionales- carecen de fuerza ilocutiva al no estar referidos al mundo real (1960: 63). Según Searle, el autor literario 
"confianza" del lector ${ }^{18}$, su credulidad, hacerle olvidar que "la novela ficcionaliza cuanto incorpora, incluso cuando se trata de sucesos o personajes reales" (Senabre 2005: 13). O en palabras del mismo Cercas que "la novela es un género que no responde ante la realidad, sino sólo ante sí mismo" (2009: 22).

En el caso de La velocidad de la luz, la identificación entre autor, narrador y personaje no es explícita sino tácita. El protagonista y narrador innominado del relato es un escritor que ha sido autor de una novela sobre la Guerra Civil que ha conocido un gran éxito de público y de crítica, una novela cuyo nombre no se da, pero se nos induce a pensar que podría ser Soldados de Salamina (Cercas 2005: 153 y 190): "Omito los pormenores de la historia, porque son públicos y más de uno los recordará todavía" (2005: 190). La clave en La velocidad de la luz es la referencia explícita a El inquilino, que se hace por dos veces en el relato (Cercas 2005: 166 y 232), y permite leer la novela como una autoficción, no explícita, sino sobreentendida. Es decir, en La velocidad de la luz la identidad nominal del protagonista con el autor de la obra se hace implícitamente, eventualidad que preveía la definición propuesta por Alberca (2009: 15).

En último lugar, la culminación de este ciclo autoficcional la hallamos en el cuento "La verdad de Agamenón" (Cercas 2006: 269-294)19. Si las autoficciones juegan con la noción de identidad personal (Alberca 2007: 33, Pozuelo Yvancos 2006: 10 y 21) 20 , o como escribe Cercas con "esa identidad -ese yo que soy yo y no soy yo al mismo tiempo-" (2000: 8), este juego de máscaras alcanza su máxima expresión en el cuento citado, donde el "Javier Cercas", autor de Soldados de Salamina, asesina al "Javier Cercas", autor de La velocidad de la luz (2006: 294), en una variación en clave de relato pseudo-policíaco ${ }^{21}$ del topos literario del doble. El doppelgänger, "el que camina al lado" en alemán, es un motivo recurrente en la literatura fantástica que simboliza el desdoblamiento de la personalidad a través de la figura del "demonio" externo (Rank 1932, Roas 2011: 88-94, Todorov 1970b: 190-192). Un demonio que a menudo vampiriza la vida del sujeto original, como en efecto sucede en el cuento de Cercas (2006: 290). A semejanza de

\footnotetext{
-de ficción- habla un lenguaje "no serio" que finge, simula, hacer afirmaciones verdaderas (Eco 1994: 85). Para la discusión en torno al estatuto lógico de los enunciados de ficción remitimos también a Eco (1984a), Genette (1991: 35-52), Hamburger (1957), Martínez Bonati (1960 y 1992), Manganelli (1985), Pozuelo Yvancos (1993: 73-86). Una muestra muy interesante de la conciencia de simulación de la fuerza ilocutiva del lenguaje no ficcional en un marco ficcional lo hallamos en Negra espalda del tiempo (Marías 1998).

18 Utilizamos aquí el concepto "Confianza (Trust)" como motor de la ficción frente al principio de "Verdad (Truth)" que rige el mundo real (Eco 1994: 98).

${ }^{19}$ La naturaleza ficcional y la intencionalidad conclusiva del relato los hallamos subrayados tanto en el subtítulo del volumen La verdad de Agamenón, "Crónicas, artículos y un cuento" (2006: 5), como en el título de la portada que precede al cuento mismo: "Un cuento (A modo de epílogo)" (2006: 267).

${ }^{20}$ Alberca ha estudiado en sus trabajos la noción de "autoficción" vinculándola a la idea de la crisis del sujeto en la cultura posmoderna (2007: 19-58).

${ }^{21}$ La estructura del relato, que se presenta como la transcripción de una suerte de interrogatorio policial, recuerda a la del cuento de Juan Benet "Obiter dictum" (2010), un autor admirado por Cercas (1998: 115).
} 
como inferimos que el éxito de Soldados de Salamina vampirizó o secuestró la vida de su autor (Cercas 2006: 58-65 y 81-90), y que como ficción se narra en La velocidad de la luz.

La naturaleza conscientemente literaria del motivo del doble, y el juego con la tradición, se explicita en las referencias a Paul Auster, Philip Roth, Poe, Dostoievski y Borges que hace el "Javier Cercas" autor de Soldados de Salamina, al saber de la existencia de su tocayo y sosias en otra ciudad (2006: 271) ${ }^{22}$. Al simbolizar, por tanto, la problematización o escisión del yo, el motivo del doble puede verse como un juego también con las nociones de autor modelo o autor implícito que postulan una entidad autorial distinta (una estrategia textual distinta) para cada uno de los textos salidos de la pluma de un mismo autor empírico (Eco 1962, 1979 y 1984b) ${ }^{23}$. ¿Quién sabe entonces si el narrador innominado en primera persona de "La verdad de Agamenón" no es acaso un tercer "Javier Cercas", distinto del de los autores de Soldados de Salamina y La velocidad de la luz?24

En "La verdad de Agamenón", lo fantástico se suma, pues, al procedimiento autofictivo con una finalidad pareja: si la autoficción induce al lector a la vacilación interpretativa mezclando lo autobiográfico y lo imaginado, lo fantástico -según lo define Todorov: "se basa esencialmente en una vacilación del lector-de un lector que se identifica con el personaje principal- referida a la naturaleza de un acontecimiento extraño" (1970b: 188)-, en el cuento de Cercas, la aparición del doble que encarna simbólicamente la escisión del sujeto, el "yo que no soy yo", el otro yo que aparece en el acto de la escritura, el otro yo mutado por el éxito.

Si por ahora hemos filiado a la autobiografía el "yo" narrativo en las obras de Cercas, veamos esos otros géneros de los que participa. Para ello nos sirve el concepto de "figuración" que avanza Pozuelo Yvancos (2010). Yvancos vincula el "yo figurado" de ciertas novelas en primera persona al "yo" del ensayo (2010: 30), un género caracterizado por la construcción de la voz de un "yo" que reflexiona y narra a la vez, y como "figurado" no se corresponde enteramente al "yo" real del autor, remitiendo por tanto a lo "fantaseado" e "imaginado", lo ficcional en suma, a lo que apunta la etimología misma de la palabra (2010: 31-35) ${ }^{25}$. A lo

${ }^{22}$ Cercas, de hecho, ya había empleado el motivo del doble en su primera novela larga El inquilino (1989).

${ }^{23}$ La noción de "autor implícito" fue ya planteada por Booth en 1961. De la bibliografía abundante sobre las nociones de "autor" o "lector", "modelo" o "implícito", queremos destacar Barthes et al (1966b), Genette (1972), Iser (1974 y 1976). De otra parte, Eco, cuyos trabajos hemos citado ya, proporciona un útil listado de referencias sobre el reader-oriented criticism (1994: 23).

24 Una lectura distinta del cuento la encontramos en Alberca (2007: 201-203). En el tríptico que componen las tres obras estudiadas es posible encontrar una huella del procedimiento empleado por Galdós para sus novelas La incógnita (1888) y Realidad (1889), dos obras conectadas entre sí y que se explican mutuamente (Cercas 1998: 48-49). Cercas, que les dedicó un ensayo (1998: 47-54), califica el procedimiento de Galdós de "espléndido" (1998: 49).

25 Dada la flexibilidad del concepto de "figuración del yo" de Pozuelo, este término se antoja quizás el más adecuado para definir la escritura de Cercas, que por su idiosincrasia difícilmente se ajusta a las tipologías autofictivas propuestas por Colonna (2004: 93-144). 
ficcional tiende también el "yo" del dietario, género del que la escritura de Cercas se nutre para las crónicas de sus "relatos reales" (2000: 7). Pensemos en lo escrito por Gimferrer: mientras el cronista consigna hechos, el escritor de dietarios, aunque los consigne, siempre se explica a sí mismo, por lo que tiene tanto de ambigüedad y tanto de seducción como la propia literatura (1981: 282-283). Los "relatos reales", recordemos, toleran ser leídos como "un dietario un tanto azaroso o desordenado, entre otras cosas porque, como en cualquier dietario, aquí se habla ante todo del yo" (Cercas 2000: 7). Lo que, evidentemente, enlaza con la programática afirmación de Montaigne en el prefacio a sus Essais: "soy yo mismo el tema de mi libro" (1998: 21).

Esta apropiación que comienza en Relatos reales de los recursos de varios géneros de no ficción articulados sobre el "yo", incluye no sólo los de la autobiografía, el ensayo o el dietario, sino los de la crónica periodística y el relato historiográfico también. En Soldados de Salamina, lo encontraremos en la biografía/ensayo/crónica de la vida de Rafael Sánchez Mazas (Cercas 2001: 77-140). O en la historia de Rodney Falk, en La velocidad de la luz, que se convierte en la crónica de la experiencia bélica de un soldado norteamericano durante la guerra del Vietnam (Cercas 2005: 85-142). Por último, en Anatomía de un instante, lo hallamos en la aplicación de las técnicas del "nuevo periodismo" (Wolfe 1973) referidas a hechos del pasado reciente, los que rodean la intentona de golpe de estado del 23-F, que Cercas se propone relatar como un cronista (2009: 25).

Anatomía de un instante se diferencia de Soldados de Salamina y La velocidad de la luz en que no es una autoficción en sentido riguroso, tal como acotábamos la noción al comienzo, ya que se presenta explícitamente como libro de no ficción: "ensayo en forma de crónica o crónica en forma de ensayo. Este libro no es una ficción" (Cercas 2009: contracubierta) ${ }^{26}$. El libro surge de una novela fallida, que el autor desiste de escribir cuando comprueba que el 23-F está ya teñido de ficción, de irrealidad (Cercas 2009: 22-25), por el recuerdo distorsionado ${ }^{27}$ en la memoria colectiva de los españoles y el amasijo de teorías conspiratorias que rodean el acontecimiento (Cercas 2009: 14-15). Pero aun sin ser una novela se emplean los recursos narrativos propios de ese género, los procedimientos de "ficcionalización" o "indicios de ficcionalización"28 (Hamburger 1957), como sucede con los "relatos factuales"29 (Genette 1991: 74-75) del "nuevo periodismo". Lo que explica la declaración de Cercas: que el libro "no renuncie del todo a ser leído como un libro de historia [...] y [...] no renuncie del todo a ser leído

\footnotetext{
${ }^{26}$ A ello responde el abundante aparato crítico en forma de notas y bibliografía que acompaña el libro (Cercas 2009: 439-462).

${ }^{27}$ El más claro: la reiteración con que se emiten periódicamente las icónicas imágenes del 23-F en el aniversario del golpe ha hecho olvidar que la televisión no lo retransmitió en directo (Cercas 2009: 15).

${ }^{28}$ Sirva de ejemplo: "Fue un lunes. El día amaneció soleado en Madrid; hacia la una y media de la tarde el sol dejó de brillar y rachas de viento invernal barrían las calles del centro; hacia las seis y media ya estaba oscureciendo" (Cercas 2009: 86).

${ }^{29}$ La asimilación del "relato factual" ("factual fiction") con el "relato real" de Cercas la establece Pozuelo Yvancos (2010: 14).
} 
como una novela" (2009: 26). De ahí que la filiación con el "nuevo periodismo" no sea ociosa: es una cita velada al subtítulo de Los ejércitos de la noche (1968), de Norman Mailer, "La Historia como una Novela. La Novela como Historia". De esa relación Cercas declara:

El New Journalism de los años sesenta pretendía, como afirmaba Tom Wolfe, que el periodismo se leyera igual que la novela, entre otras razones porque usaba las estrategias de la novela, pero el resultado no fue sólo que el periodismo canibalizó la novela, sino también que la novela canibalizó el periodismo, digiriendo los recursos de éste y convirtiendo la materia periodística en materia de novela. (Cercas 2011)

Tal vez a Anatomía de un instante le convendría entonces el marbete de "novela de no ficción", acuñado por Truman Capote, o mejor, libro de no ficción escrito como una novela. De la porosidad de la novela, su capacidad proteica de incorporar los recursos de otros géneros literarios, de mezclar lo real con lo ficcional, es algo de lo que Cercas es plenamente consciente y sobre lo que ha reflexionado en sus ensayos (1998: 113-133, 2006: 95-100, 101-105 y 251). Ese género que no tiene de suyo una definición clara y unívoca, y cuya elasticidad no posee ningún otro género literario en igual proporción (Senabre 2005: 13) ${ }^{30}$, le ha servido para dar cauce a los dos ejes de su obra: el autobiográfico, la reflexión sobre el yo, y el histórico-cronístico, la reflexión sobre los acontecimientos externos. Así, Soldados de Salamina es tanto una novela sobre la Guerra Civil, la crónica de las vidas de un falangista y un republicano, como una novela sobre un escritor mediocre que debe forcejear con sus limitaciones. La velocidad de la luz, es una novela sobre un escritor víctima de su éxito y a la vez una novela sobre el Vietnam y la historia reciente de América. Como Anatomía de un instante es un libro sobre el 23-F, y un libro escrito para comprender a los hombres de la generación de Adolfo Suárez, tibia y residualmente franquistas, como lo era el propio padre de Javier Cercas (2009: 18-19 y 436-437).

Para entender la relación entre esos dos ámbitos a los que alude la obra de Cercas, el histórico y el personal, resulta útil el estudio de la imbricación del discurso narrativo con la representación histórica acometido por Hayden White $(1987)^{31}$. Para White la única significación de la historia es la que le otorga una imaginación narrativa, pues el discurso historiográfico, como el ficcional, otorga coherencia a una serie de hechos acontecidos (1987: 74-78). También Ricoeur ha examinado el vínculo entre narración e historiografía a propósito de la intencio-

\footnotetext{
30 Senabre habla de "género de aluvión" para la novela -Cercas emplea el mismo símil (2006: 251)-: por su aparición tardía en la historia de la literatura es intrínseco a su naturaleza incorporar hallazgos y recursos de muchos otros géneros (2004: 13). D. Villanueva escribe que la única norma del género es transgredirlas todas y experimentar con todas las transgresiones (1977: 15). De ese permanente estado de conformación deducía Bajtin la inagotable capacidad de renovación de la novela y su supremacía como género literario moderno (1975: 441-485).

31 White argumenta, siguiendo a Barthes (1984: 163-177), que, pese a la pretensión científica de la historiografía, el discurso histórico comparte una misma matriz con la narración ficcional (1987: 42-74).
} 
nalidad del relato historiográfico (1984: 290-364). Según Ricoeur, la narración es un acto de construcción que configura unos acontecimientos dispersos, los hace historia (1984: 133). Lo mismo que la novela dota a los hechos que narra de una coherencia que los hace inteligibles, y por esa razón Anatomía de un instante era un libro que no renunciaba a ser leído como una novela (Cercas 2009: 25-26).

De ahí que la obra de Cercas se adecúe al concepto de "metaficción historiográfica" desarrollado por Linda Hutcheon (1988 y 1989) ${ }^{32}$. Partiendo de las tesis de White y Ricoeur, David K. Herzberger (1995), ha explicado el discurso sobre el pasado de muchos narradores durante el franquismo y la Transición: mientras la historiografía franquista postuló una visión cerrada y autoritaria de la noción de "verdad histórica"33 (1995: 15-38), los escritores que en sus obras se propusieron abordar la representación del pasado, lo hicieron en oposición al discurso oficial, subvirtiendo los principios narrativos mismos de la historiografía

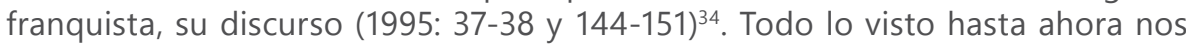
permite contemplar la obra de Cercas en la órbita de la de esos predecesores ${ }^{35}$, que ejemplifican cómo, según Herzberger, el pasado es materia interpretable pero nunca puede ser interpretado de manera cerrada y definitiva (1995: 9). Al problematizar la noción de verdad referencial sobre el pasado (Herzberger 1995: 116-143), esta clase de ficciones que, empleada la terminología de Hutcheon podríamos Ilamar "metaficciones historiográficas", se vinculan con la autoficción en la medida en que ambas ponen de relieve las fisuras de dos entidades comúnmente tenidas por sólidas: la verdad "objetiva" de la historiografía en el primer caso, la identidad personal en el segundo ${ }^{36}$. En la obra de Javier Cercas, como hemos intentado mostrar, conviven ambos proyectos. Por eso, si Doubrovsky

32 Esta clase de ficción muestra la necesidad de construir una representación del pasado necesariamente tentativa y parcial, y por ello elabora un discurso opuesto a una visión totalizadora y unívoca de la historia (Hutcheon 1989: 62-70). Así, dichas representaciones construyen mundos de ficción que participan también del ámbito de la experiencia pública, sin pretensiones de reproducir la realidad de manera simplista, sino que se ofrecen como uno de los discursos mediante los cuales construimos nuestras versiones de la realidad, algo que tanto la narrativa realista como el relato historiográfico soslayan (Hutcheon 1988: 105-123).

33 Un elemento que coincide con la concepción de la escritura como búsqueda de la verdad, según la entiende Cercas (Arpaia 2013).

${ }^{34}$ Referencia inexcusable para el estudio de la vida intelectual bajo el franquismo es Jordan (1990), así como más recientemente Gracia (2004).

35 Sería interesante establecer una filiación de la obra de Cercas con una novela como El cuarto de atrás (Martín Gaite 1978), relato claramente autoficcional donde la autora teje su propia memoria sentimental con la memoria colectiva de la Guerra Civil y la España franquista. Aunque no hay que olvidar que la mirada sobre el pasado se hace desde el lugar histórico de generaciones distintas (Gracia y Ródenas 2011: 8-9).

36 Samuel Amago propone "self-conscious historiography" en su estudio sobre Soldados de Salamina (2006: 156-159), un trabajo que coincide en algunos puntos con nuestra lectura, si bien pasa de soslayo el resto de la obra de Cercas, y no tiene en cuenta a los predecesores españoles, excepto la vinculación que establece entre la novela de Cercas y Negra espalda del tiempo en lo que hace a la confusión buscada entre autor y narrador (2006: 144). De su parte, Lozano Mijares sí emplea el concepto de "metaficción historiográfica" y lo sitúa como uno de los modos narrativos más utilizados de la literatura española posmoderna; aunque no atiende en su trabajo a los escritos de Cercas (2007: 287-313). 
sostenía que la autoficción no percibe la vida como un todo (1977: contracubierta), la autoficción en Cercas no sólo no percibe la vida como un todo, sino que tampoco lo hace con la historia, con el pasado colectivo.

\section{OBRAS CITADAS}

Alberca, Manuel (1996): "¿Es literario el género autobiográfico? Tres ejemplos actuales". En: José María Pozuelo Yvancos y Francisco Vicente Gómez (eds.): Mundos de ficción. Universidad de Murcia, pp. 175-184.

_ (1999): "En las fronteras de la autobiografía". En: Mario Ledesma Pedraz (ed.): Escritura autobiográfica y géneros literarios. Universidad de Jaén, pp. 53-75.

- (2007): El pacto ambiguo. De la novela autobiográfica a la autoficción. Madrid, Biblioteca Nueva.

- (2009): "El pacto ambiguo (bonus track)", Ínsula, n. ${ }^{\circ}$ 754, pp. 14-18.

Amago, Samuel (2006): True Lies. Narrative Self-Consciousness in the Contemporary Spanish Novel. Lewisburg, Bucknell University Press, pp. 144-165.

Aristóteles (1953): Retórica. Madrid, Centro de Estudios Constitucionales.

- (2002): Poética. Madrid, Istmo.

Arpaia, Bruno (ed.) (2013): Dedica a Javier Cercas. Pordenone, Dedica.

Auerbach, Erich (1942): Mímesis. México, Fondo de Cultura Económica.

Austin, John (1960): Palabras y acciones. Barcelona, Paidós.

Bajtin, Mijail (1975): Teoría y estética de la novela. Madrid, Taurus.

Barthes, Roland (1966a): Crítica y verdad. Buenos Aires, Siglo xxI.

— et al. (1966b): Análisis estructural del relato. Barcelona, Ediciones Buenos Aires.

- (1984): El susurro del lenguaje. Barcelona, Paidós.

Benet, Juan (2010): "Obiter dictum". En: Así era entonces. Cuentos completos 2. Barcelona, Debolsillo, pp. 201-214.

Booth, Wayne C. (1961): The Rhetoric of Fiction. Londres, Penguin Books.

Caballé, Anna (1995): Narcisos de tinta: ensayos sobre la literatura autobiográfica en lengua castellana (siglos XIX $y x x$ ). Málaga, Megazul.

— (1999): "La ilusión biográfica". En: Mario Ledesma Pedraz (ed.): Escritura autobiográfica y géneros literarios. Universidad de Jaén, pp. 21-33.

Cercas, Javier (1987): El móvil. Barcelona, Tusquets.

- (1989): El inquilino. Barcelona, El Acantilado.

- (1993): La obra literaria de Gonzalo Suárez. Barcelona, Sirmio.

- (1997): El vientre de la ballena. Barcelona, Tusquets.

- (1998): Una buena temporada. Editora Regional de Extremadura.

- (2000): Relatos reales. Barcelona, El Acantilado.

- (2001): Soldados de Salamina. Barcelona, Tusquets.

- (2005): La velocidad de la luz. Barcelona, Tusquets.

- (2006): La verdad de Agamenón. Barcelona, Tusquets.

- (2009): Anatomía de un instante. Barcelona, Random House-Mondadori.

— (2011): "La tercera verdad". Disponible en <http://www.elpais.com/diario/2011/06/25/ babelia/130890747850215.html>. Última visita: 22.10 .13 
— y Arpaia, Bruno (2013): L'avventura di escrivere romanzi. Parma, Ugo Guanda.

Colonna, Vincent (2004): Autofiction \& autres mythomanies littéraires. París, Tristram.

Doubrovsky, Serge (1977): Fils. París, Galilée.

Genette, Gérard (1972): Figuras III. Barcelona, Lumen.

— (1977): "Géneros, "tipos", modos". En: Miguel Ángel Garrido Gallardo (ed.): Teoría de los géneros literarios. Madrid, Arco Libros, pp. 183-233.

(1991): Ficción y dicción. Barcelona, Lumen.

Gimferrer, Pere (1981): Dietari. 1979-1980. Barcelona, Edicions 62.

Gracia, Jordi (2001): Hijos de la razón. Madrid, Edhasa.

- (2004): La resistencia silenciosa. Barcelona, Anagrama.

Gracia, Jordi, y Ródenas, Domingo (2011): Derrota y restitución de la modernidad (1939-

2010). En: José-Carlos Mainer (ed.): Historia de la literatura española, vol. 7. Barcelona, Crítica.

Eco, Umberto (1962): Obra abierta. Barcelona, Ariel.

- (1979): Lector in fabula. Barcelona, Lumen.

- (1984a): Semiótica y filosofía del lenguaje. Barcelona, Lumen.

— (1984b): The Role of the Reader. Bloomington, Indiana University Press.

_ (1994): Seis paseos por los bosques narrativos. Barcelona, Lumen.

Fowler, Alistair (1982): Kinds of Literature. Oxford University Press.

Frye, Northrop (1977): Anatomía de la crítica. Caracas, Monte Ávila.

Herzberger, David K. (1995): Narrating the Past. Fiction and Historiography in Postwar

Spain. Durham/Londres, Duke University Press.

Hamburger, Käte (1957): Logique des genres littéraires. París, Seuil.

Hutcheon, Linda (1988): A Poetics of Postmodernism: History, Theory, Fiction. Nueva York/

Londres, Routledge.

_ (1989): Politics of Postmodernism. Londres, Routledge.

Iser, Wolfgang (1974): The Implied Reader. Baltimore, John Hopkins University Press.

- (1976): El acto de leer. Madrid, Taurus.

Jauss, Hans Robert (1970): La historia de la literatura como provocación. Barcelona, Península.

Jordan, Barry (1990): Writing and Politics in Franco's Spain. Londres/Nueva York, Routledge.

Lecarme, Jacques (1993): "Autofiction: un mauvais genre?", Autofictions \& Cie. Ritm, n. 6 , pp. 227-249.

Lejeune, Phillippe (1975): Le pacte autobiographique. París, Seuil.

- (1986): Moi aussi. París, Seuil.

Lozano Mijares, Mº del Pilar (2007): La novela española posmoderna. Madrid, Arco Libros.

Mailer, Norman (1968): Los ejércitos de la noche. Barcelona, Anagrama.

Manganelli, Giorgio (1985): "La literatura como mentira". En: Basilio Baltasar (ed.): Críticas ejemplares. Palma de Mallorca, Bitzoc, pp. 159-166.

Marchese, Angelo (1978): Diccionario de retórica, crítica y terminología literaria. Barcelona, Ariel.

Marías, Javier (1998): Negra espalda del tiempo. Madrid, Alfaguara.

Martín Gaite, Carmen (1978): El cuarto de atrás. Barcelona, Destino.

Martínez Bonati, Félix (1960): La estructura de la obra literaria. Barcelona, Ariel.

134 | Pasavento. Revista de Estudios Hispánicos, vol. III, n. ${ }^{1}$ (invierno 2015), pp. 123-135, ISSN: 2255-4505 
- (1992): La ficción narrativa (Su lógica y ontología). Universidad de Murcia.

Montaigne, Michel (de) (1998): Un libro de buena fe. Ensayos. Barcelona, Península.

Pavel, Thomas (2003): Representar la existencia. El pensamiento en la novela. Barcelona,

Crítica.

Pozuelo Yvancos, José María (1988): Teoría del lenguaje literario. Madrid, Cátedra.

- (1993): Poética de la ficción. Madrid, Síntesis.

- (2004): Ventanas de la ficción. Narrativa hispánica, siglos xx y xxı. Barcelona, Península.

- (2006): De la autobiografía: teoría y estilos. Barcelona, Crítica.

- (2010): Figuraciones del yo en la narrativa. Javier Marías y Enrique Vila-Matas.

Universidad de Valladolid.

Rank, Otto (1932): Don Juan et le double. París, Payot.

Ricoeur, Paul (1984): Tiempo y narración. Madrid, Siglo xxı.

Rimmon-Kenan, Shlomith (1983): Narrative Fiction. Contemporary Poetics. Nueva York, Routledge.

Roas, David (2011): Tras los límites de lo real. Madrid, Páginas de Espuma.

Senabre, Ricardo (2005): Metáfora y novela. Universidad de Valladolid.

Starobinski, Jean (1970): La relación crítica (psicoanálisis y literatura). Madrid, Taurus.

Tatarkiewiwcz, Wladislaw (1976): Historia de seis ideas. Arte, belleza, forma, creatividad, mímesis, experiencia estética. Madrid, Tecnos.

Todorov, Tzvetan (1970a): L'énonciation. París, Didier/Larousse.

— (1970b): Introducción a la literatura fantástica. Barcelona, Ediciones Buenos Aires.

- (1971): Literatura y significación. Barcelona, Planeta.

- (1978): Genres in discourse. Cambridge University Press.

Villanueva, Darío (1977): Estructura y tiempo reducido en la novela. Barcelona, Anthropos.

— (1989): El comentario de textos narrativos: la novela. Valladolid/Gijón, Aceña/Júcar.

- (2004): Teorías del realismo literario. Madrid, Biblioteca Nueva.

Wellek, René y Warren, Austin (1949): Teoría literaria. Madrid, Gredos.

White, Hayden (1987): El contenido de la forma: narrativa, discurso y representación histórica. Barcelona, Paidós.

Wolfe, Thomas (1973): El nuevo periodismo. Barcelona, Anagrama. 